\title{
Dimethyl Fumarate's Effectiveness and Safety in Psoriasis: A Real-Life Experience During the COVID- 19 Pandemic
}

\author{
Maria Esposito (D) - Anna Campanati · Alessandro Giunta • \\ Gianluca Calianno · Luca Bianchi · Federico Diotallevi • \\ Anna Maria Offidani · Maria Concetta Fargnoli
}

Received: October 21, 2021 / Accepted: January 17, 2022 / Published online: February 1, 2022

(C) The Author(s) 2022

\begin{abstract}
Introduction: Dimethyl fumarate (DMF) is approved as oral systemic treatment for moderate-to-severe psoriasis. Scarce evidence is available for DMF treatment in psoriatic patients at the time of COVID-19 pandemic. The objective of this study was to assess the long-term effectiveness and safety of DMF monotherapy in moderate-to-severe psoriasis during the COVID-19 pandemic period.

Methods: This multicenter, retrospective study included patients with moderate-to-severe psoriasis who had received a 48 -week DMF treatment during the COVID-19 pandemic. Selected outcomes were: variation of mean PASI, proportion of patients achieving PASI50 and PASI75, variation of mean PGA and face PGA,
\end{abstract}

Maria Esposito and Anna Campanati contributed equally.

M. Esposito $(\bowtie) \cdot$ G. Calianno · M. C. Fargnoli Dermatology Unit, Department of Biotechnological and Applied Clinical Sciences, University of

L'Aquila, via Vetoio-Coppito 2, 67100 L'Aquila, Italy e-mail: maria.esposito3@univaq.it

A. Campanati · F. Diotallevi · A. M. Offidani Dermatological Clinic, Department of Clinical and Molecular Sciences, Polytechnic Marche University, Ancona, Italy

A. Giunta $\cdot$ L. Bianchi

Department of Dermatology, University of Rome

Tor Vergata, Rome, Italy genital PGA, scalp PGA, mean itch VAS and mean DLQI.

Results: Forty-four patients were enrolled, and four patients became COVID-19 positive during the observation period but did not discontinue DMF therapy. DMF produced a significant improvement of signs and symptoms of psoriasis as expressed by mean PASI variation from 13.07 at baseline to 6.11 at week 48 $(p<0.0001)$, itch VAS from 3.22 at baseline to 1.18 at week $48(p<0.001)$, PGA from 2.84 at baseline to 1.30 at week $48(p<0.0001)$ and DLQI from 13.09 at baseline to 6.07 at week 48 $(p<0.0001)$. The percentage of patients who achieved PASI50 and PASI75 was $4.55 \%$ at week 4 and $59.09 \%$ at week 48 and $0 \%$ at week 4 and $22.73 \%$ at week 48 , respectively. A clinical important decrease of mean PGA score was observed in all subgroups, face psoriasis, genital psoriasis and scalp psoriasis. Adverse events were predictable and manageable.

Conclusions: DMF monotherapy is an effective and safe treatment option in moderate-to-severe psoriasis also in patients who develop SARSCoV-2 infection.

Keywords: Dimethyl fumarate; COVID-19 pandemic; Psoriasis; Quality of life 


\section{Key Summary Points}

Why carry out this study?

Among first-line treatments for psoriasis, dimethyl fumarate (DMF) demonstrated a favorable efficacy and safety profile in short- and long-term observation; however, scarce evidence is available for DMF treatment in real-life practice at the time of the COVID-19 pandemic

It has been suggested that the immunomodulatory, anti-oxidative and anti-inflammatory properties of DMF could reduce the cytokine storm caused by severe COVID-19

We aimed to assess the long-term effectiveness and safety of DMF monotherapy in moderate-to-severe psoriasis patients during the COVID-19 pandemic period

\section{What was learned from the study?}

DMF monotherapy significantly improved all disease activity indexes showing a good safety profile and an optimal drug survival rate

DMF monotherapy was an effective and safe treatment option in moderate-tosevere psoriasis also in four patients who developed SARS-CoV-2 infection

\section{INTRODUCTION}

Psoriasis is a chronic inflammatory skin disease with systemic manifestations that affects between $\sim 2 \%$ and $4 \%$ of the Western population. Psoriasis is usually accompanied by substantial quality of life (QoL) impairment [1-5].

Dimethyl fumarate (DMF) is a methyl ester of fumaric acid (chemical formula $\mathrm{C}_{6} \mathrm{H}_{8} \mathrm{O}_{4}$ ) that is hydrolyzed in the small intestine to the active metabolite monomethyl fumarate, approved for the treatment of moderate-to-severe plaque psoriasis $[6,7]$. DMF is known to exert anti-inflammatory, anti-oxidative and immunomodulatory effects primarily through three molecular pathways: (1) activation of nuclear factor erythroid 2-related factor 2 (Nrf2), which binds to the antioxidant response element in the nucleus to stimulate transcription of phase II enzymes [superoxide dismutase, NAD(P)H quinone oxidoreductase- 1 and heme oxygenase-1]; (2) inhibition of nuclear factor kappa B (NF- $\kappa \mathrm{B})$, which prevents the translocation of NF- $\kappa B$ into the nucleus, the release of pro-inflammatory cytokines and subsequent inflammation and damage; (3) immunomodulatory effects through hydroxycarboxylic acid receptor 2 $[2,6,8,9]$.

Several clinical randomized and observational studies have demonstrated that DMF, among oral traditional systemic agents, presents clinical long-term efficacy and favorable safety profile [1-3, 5]. A recent European Expert Consensus proposed DMF as a first-line therapeutic option to achieve sustained disease control for patients with moderate-to-severe plaque psoriasis when psoriasis cannot be adequately controlled with topical treatments and phototherapy [3, 10-15].

Scarce evidence is available for DMF treatment in psoriatic patients in real-life practice, in particular at the time of the COVID-19 pandemic. Therefore, the aim of this study was to assess the long-term effectiveness and safety profile of DMF monotherapy in patients with moderate-to-severe psoriasis during the COVID19 pandemic.

\section{METHODS}

\section{Study Design}

Multicenter, retrospective, real-life study conducted at the Departments of Dermatology of the University of L'Aquila and Ancona, Italy.

\section{Patients}

Consecutive adult patients with moderate-tosevere psoriasis unresponsive to topical 
treatment, phototherapy and/or conventional treatments for psoriasis, undergoing DMF treatment according to the National and International Guidelines [15], starting treatment from January to September 2020, were included in the study. Patients had to be treated with DMF as monotherapy, as reported in the summary of product characteristics (SPCs), and followed for an observation period of 48 weeks [16]. The investigation was conducted in accordance with the Helsinki Declaration, and patients signed a declaration allowing the use of clinical records for scientific purposes. Ethics committee approval for retrospective studies was not required.

\section{Assessments, Endpoints and Follow-Up Procedures}

Prior to DMF therapy, demographic characteristics, previous anti-psoriatic treatments, comorbidities, clinical characteristics including Psoriasis Area Severity Index (PASI) [17] [range 0 (no disease) to 72 (maximal disease)], Physician Global Assessment (PGA) [18], face PGA, genital PGA, scalp PGA [PGA range 0 (no symptom) to 5 (severe symptoms)], itch VAS (visual analog scale) [range 0 (no symptom) to 10 (severe symptoms)], Dermatology Life Quality Index (DLQI) [19] [range 0 (no effect at all on patient's quality of life) to 30 (extremely large effect on patient's quality of life)]. Routine laboratory assessments including lymphocyte and neutrophil count, neutrophil-to-lymphocyte ratio (NLR), C-reactive protein (CRP), erythrocyte sedimentation rate (ESR), were obtained for all participants. All patients underwent a COVID19 rapid nasopharyngeal swab test from September 2020 to December 2020 and were asked to communicate the results to the referring specialist. Effectiveness was assessed as improvement vs. baseline in PASI, PGA, itch VAS and DLQI and by evaluating the proportion of patients achieving PASI50 ( $\geq 50 \%$ improvement of PASI from baseline) and PASI75 ( $\geq 75 \%$ improvement of PASI from baseline). Safety profile and treatment survival rate were monitored at each visit.
Patients starting DMF monotherapy were routinely followed for $4,12,24$ and 48 months.

\section{DMF Treatment Protocol}

DMF, as gastro-resistant tablets, was prescribed as routine clinical practice, in accordance with the SPCs. During the first week, DMF $30 \mathrm{mg}$ was taken once a day ( 1 tablet in the evening), from the second week, DMF $30 \mathrm{mg}$ was taken twice a day ( 1 tablet in the morning and 1 tablet in the evening), and from the third week, DMF $30 \mathrm{mg}$ was taken three times a day (1 tablet in the morning, 1 at noon and 1 in the evening). From the fourth week onwards, treatment switched to one tablet of DMF $120 \mathrm{mg}$ in the evening. This dose was then increased by one tablet of DMF $120 \mathrm{mg}$ per week at different times of the day for the next 5 weeks. The maximum permitted daily dose was $720 \mathrm{mg}$ ( 2 tablets of DMF $120 \mathrm{mg}$ 3 times a day) [16].

\section{Data Analysis}

Statistical analysis was performed using a software (GraphPad, San Diego, CA, USA). Imputation of missing data (IMD) was performed by last observation carried forward (LOCF) analysis. Paired Student $t$-test comparing baseline values to each time point (weeks 4, 12, 24 and 48) was used. Data are presented as percentage change vs. baseline for PASI, PGA, itch VAS, DLQI; mean \pm standard deviation (SD) for PGA score in the subgroups: face psoriasis, genital psoriasis and scalp psoriasis; proportion of patients achieving $\geq 50 \%$ improvement of PASI or $\geq 75 \%$ (PASI 50, PASI 75).

\section{RESULTS}

\section{Study Population}

A total of 44 patients satisfied the inclusion criteria and were enrolled in the study. The mean age at the start of DMF monotherapy was 50.48 years (range $22-75$ ); $65.91 \%$ of the patients were male. The mean body mass index (BMI) was 25.44 (range 20.24-31.46) kg/m². All 
patients had plaque-type psoriasis. Concerning previous anti-psoriatic therapy, 70.45\% received topical treatment, $11.36 \%$ phototherapy and $43.18 \%$ systemic agents such as ciclosporin (22.73\%), acitretin (15.91\%), methotrexate (11.36\%), adalimumab, etanercept and apremilast (2.27\%). Difficult-to-treat psoriasis localizations were involved as follows: scalp (56.82\%), nails $(20.45 \%)$, face $(13.64 \%)$, genitals and palmoplantar area $(9.09 \%)$.

The most common comorbidities were hypertension (29.55\%), hypercholesterolemia (22.73\%) and type 2 diabetes (13.64\%). Clinical characteristics and peripheral blood hematological parameters are reported in Table 1.

Table 1 Patients' clinical and hematological characteristics at baseline

Mean clinical characteristics, $n$ (range)

$\begin{array}{ll}\text { PASI }(0-72) & 13.07(6.8-56.2) \\ \text { PGA }(0-5) & 2.84(1-5) \\ \text { Itch VAS }(0-10) & 3.22(0-10) \\ \text { DLQI }(0-30) & 13.09(2-23) \\ \text { PGA-face }(0-5) & 2(1-5) \\ \text { PGA-genital }(0-5) & 3.5(3-4) \\ \text { PGA-scalp }(0-5) & 2.84(1-5) \\ \text { Mean peripheral blood hematological } & \text { parameters, } \\ n \text { (range) } & 2.83(1.3-4.92) \\ \text { Lymphocytes }\left(\times 10^{\wedge} 3 / \mu \mathrm{l}\right) & 5.78(2.63-8.2) \\ \text { Neutrophils }\left(\times 10^{\wedge} 3 / \mu \mathrm{l}\right) & 2,20(0.86-5.15) \\ \text { NLR, } n & 2.98(0.1-78) \\ \text { CRP (mg/dl) } & 15.11(2-57) \\ \text { ESR (mm/h) }\end{array}$

PASI Psoriasis Area Severity Index, PGA Physician Global Assessment, $V A S$ visual analog scale, DLQI Dermatology Life Quality Index, NLR neutrophil-to-lymphocyte ratio, $C R P$ C-reactive protein, ESR erythrocyte sedimentation rate

\section{DMF Usage}

Single maximum dosages, corresponding to the minimum effective dose or the maximum tolerated dose maintained by each patient, were $90 \mathrm{mg}$ for 2 patients, $120 \mathrm{mg}$ for 9 patients, $240 \mathrm{mg}$ for 3 patients, $360 \mathrm{mg}$ for 20 patients, $480 \mathrm{mg}$ for 8 patients, $600 \mathrm{mg}$ for 1 patient and $720 \mathrm{mg}$ for 1 patient.

\section{Effectiveness}

DMF produced a significant improvement of mean PASI from baseline starting from week 12 and maintained until week $48 \quad(p<0.0001)$ (Fig. 1). The mean PASI value (mean $\pm \mathrm{SD}$ ) varied from $13.07 \pm 7.35$ at baseline to $10.26 \pm 4.37$ at week 4 , to $8.07 \pm 3.74$ at week 12 , to $6.58 \pm 5.12$ at week 24 and $6.11 \pm 5.22$ at week 48 . The percentage of patients who achieved PASI50 was $4.55 \%$ at week $4,20.45 \%$, at week $12,54.55 \%$ at week 24 and $59.09 \%$ at the end of observation period (week 48) (Fig. 2). The percentage of patients who achieved PASI75 was $0 \%$ at week $4,6.82 \%$ at week 12 , $18.18 \%$ at week 24 and $22.73 \%$ at the end of the observation period (week 48) (Fig. 2). Similar results were observed for mean PGA with a mean reduction from baseline of $-20.07 \%$, $-33.45 \%,-49.64 \%$ and $-54.22 \%$ at week 4 , $12,24$ and 48, respectively ( $p<0.0001)$ (Fig. 1). Furthermore, DMF treatment significantly reduced mean itch VAS, which varied from $3.22 \pm 3.02(\mathrm{SD})$ at baseline to $2.34 \pm 2.57$ (SD) at week 4, $1.52 \pm 2.28$ (SD) at week 12 , $1.19 \pm 2.30$ at week 24 and $1.18 \pm 2.32$ (week 48) (-63.25\%; $p<0.001)$ (Fig. 1). Regarding quality of life, as measured by mean DLQI, a significant improvement was already seen at week 4 with a score reduction of $20.85 \%$ $(p<0.0001)$. An increase in improvement in mean DLQI was observed at the different visits, week 4, 12, 24 and 48 (Fig. 1). More specifically, the mean DLQI decreased from $13.09 \pm 5.96$ (SD) at baseline to $10.36 \pm 4.85$ (SD) at week 4 , to $7.86 \pm 4.82(\mathrm{SD})$ at week 12 , to $6.36 \pm 5.95$ (SD) at week 24 and to $6.07 \pm 5.97$ at week 48 $(p<0.0001)$. A clinically significant benefit was 


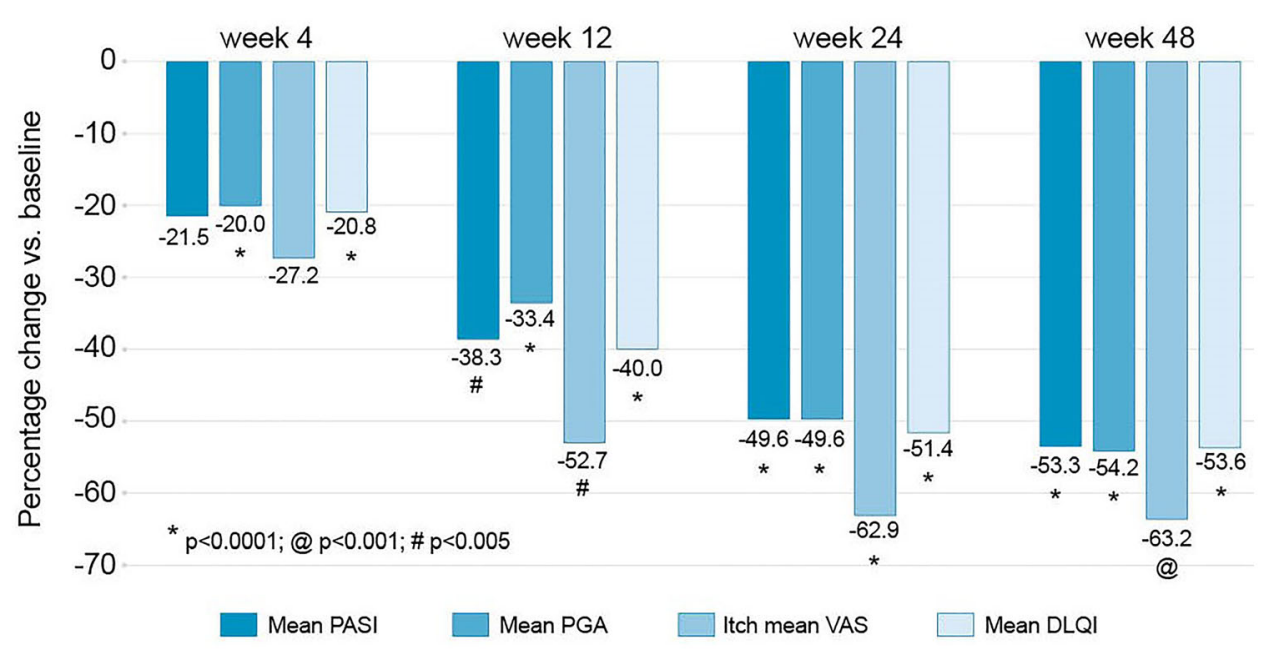

Fig. 1 Variation of clinical and DLQI scores during DMF treatment expressed as percentage change vs. baseline of PASI, PGA, itch VAS, DLQI. PASI Psoriasis Area Severity

Index, $P G A$ Physician Global Assessment, VAS visual analog scale, $D L Q I$ Dermatology Life Quality Index

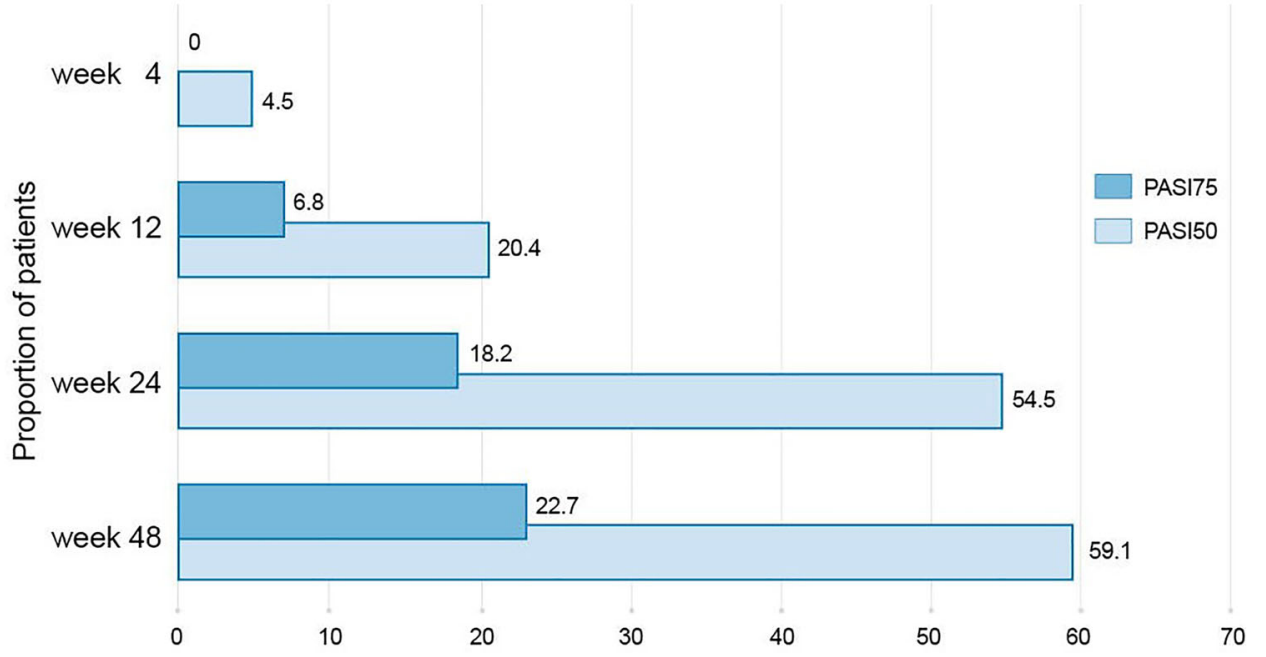

Fig. 2 Proportion of patients achieving $\geq 50 \%$ improvement in Psoriasis Area and Severity Index (PASI 50) and PASI 75 at week 4, week 12, week 24, week 48. PASI50

observed at the end of the study (48 weeks) (Fig. 3).

An analysis of mean PGA improvement, depending on difficult sites, was performed. A clinical important decrease of mean PGA score was observed in all subgroups, face psoriasis, genital psoriasis and scalp psoriasis (Fig. 4). $\geq 50 \%$ improvement in Psoriasis Area and Severity Index vs. baseline, PASI75 $\geq 75 \%$ improvement in Psoriasis Area and Severity Index vs. baseline

\section{Safety}

\section{Hematological Parameters}

Neutrophil count remained stable over the course of the study; in particular, $5.78 \times 10^{\wedge} 3 / \mu \mathrm{l}$ at the baseline visit and $5.45 \times 10^{\wedge} 3 / \mu \mathrm{l}$ after 48 weeks $(p=0.5058)$. Similar results were observed for the NLR with a baseline value of 2.19 and 2.76 after 48 weeks $(p=0.2713)$. 

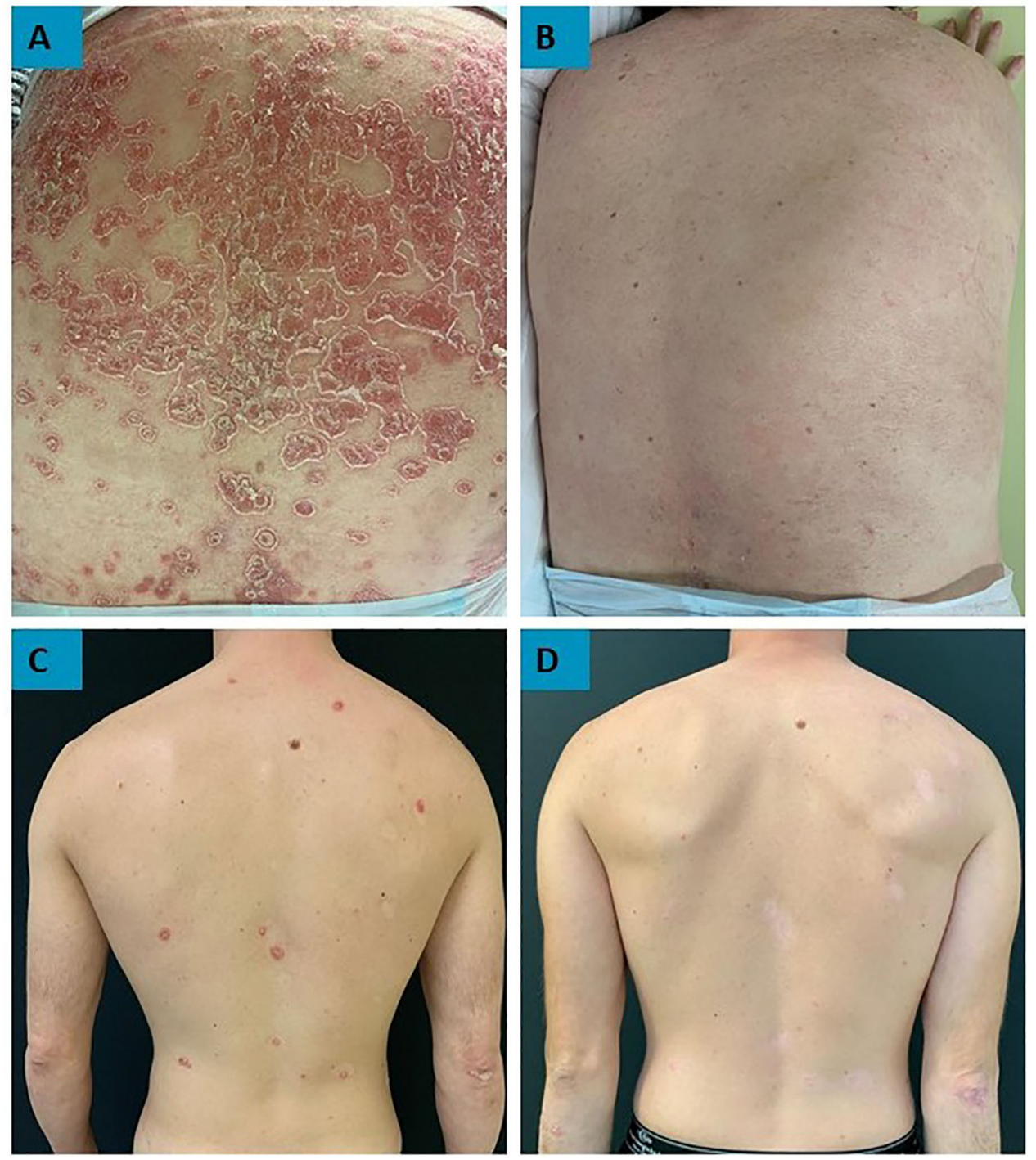

Fig. 3 Clinical improvement of psoriasis with DMF treatment in a 73-year-old woman presenting baseline PASI 46 (A) reduced to PASI 0 at week 48 (B) and in a

30-year-old male patient presenting baseline PASI 12 (C) reduced to PASI 0 at week 48 (D)

\section{Adverse Events and Dropouts}

One hundred fourteen adverse events were observed with $75 \%$ of patients experiencing at least one adverse event. The most common adverse events were flushing (54.55\%), diarrhea (43.18\%), gastric pain $(29.33 \%)$, persistent diarrhea (> 8 weeks) (15.91\%), anorexia (13.64\%), and nausea, hair loss and depression $<10 \%$. Considering flushing and gastrointestinal effects, which were the most common side effects, they were mild and transient in most cases, while in a minority of cases,

corresponding to higher severity forms, a dose reduction strategy was adopted to limit the effect.

\section{SARS-CoV-2 Infection}

All patients underwent COVID-19 screening with a rapid nasopharyngeal swab test between September and December 2020 (baseline visit) with negative results. Six patients, for personal or occupational reasons, performed $\operatorname{IgG} / \operatorname{IgM}$ COVID-19 tests during the study period, and the results were negative. Thereafter, only 4 of 


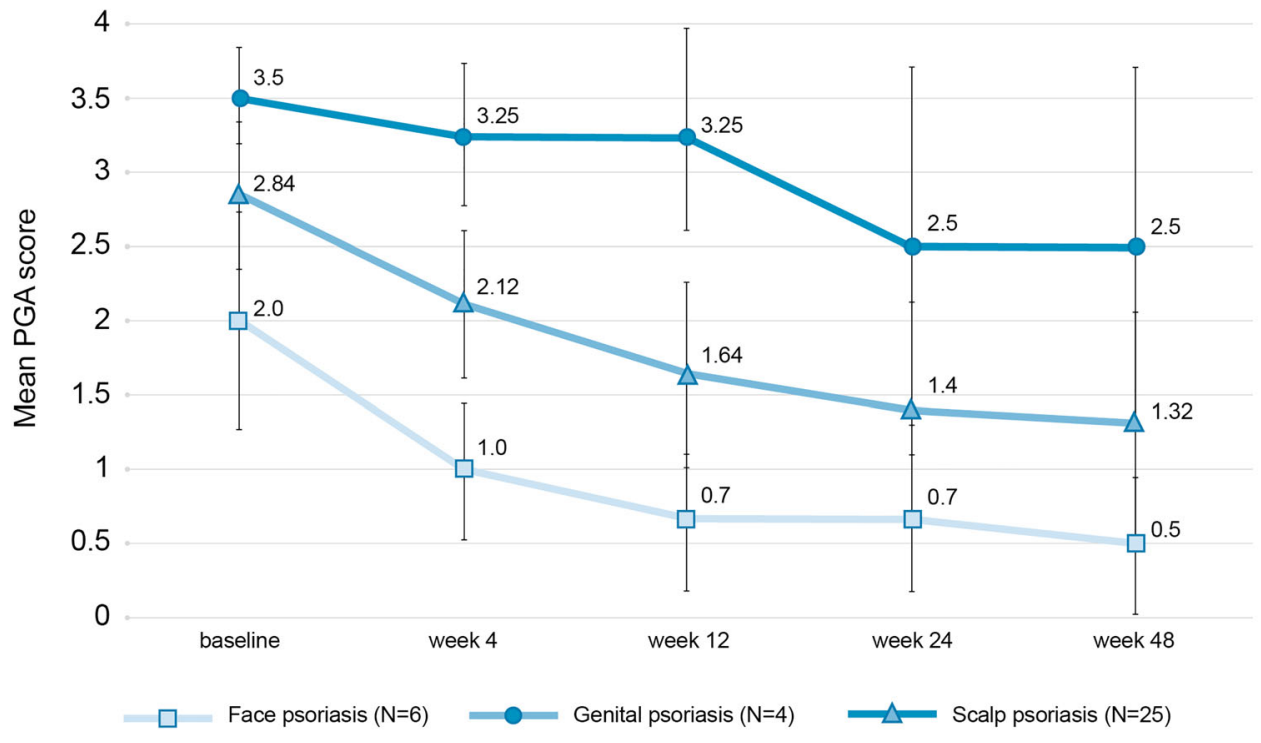

PGA: Physician Global Assessment.

Fig. 4 Mean PGA score \pm SD over time at different psoriasis sites during DMF treatment

44 patients developed COVID-19 positivity during the study period.

All four patients were male, aged between 53 and 67 years, with a BMI between $24.8-28.4 \mathrm{~kg} /$ $\mathrm{m}^{2}$ (Table 2). During DMF treatment, they developed a mild form of COVID-19. The presence of SARS-CoV-2 infection did not cause discontinuation of DMF treatment.

\section{Treatment Survival Rate}

At the end of the follow-up period (week 48), $70.45 \%$ remained on treatment with a dropout percentage of $29.55 \%$.

In total, there were 13/44 dropouts: week 4: seven dropouts, four because of poor compliance, two because of nausea and gastric symptoms and one because of mood alteration and acute defluvium in the same patient; week 12: two discontinuations, one because of gastric symptoms and one because of ineffectiveness; week 24: four dropouts because of inefficacy.

\section{DISCUSSION}

This retrospective study demonstrated that DMF monotherapy significantly improved all evaluated psoriasis disease activity indexes, e.g., PASI, PGA and itch VAS. A sub-analysis according to psoriasis sites demonstrated an important clinical reduction of mean PGA referring to face, genital and scalp psoriasis, known as difficultto-treat areas. Moreover, $>50 \%$ of patients reached PASI50 at week 24 , which was maintained until week 48 , and $>20 \%$ reached PASI75 at week 48 . The effectiveness in controlling and reducing psoriatic symptoms was consistent as expressed by the reduction of itch VAS and resulted in significant improvement in patients' quality of life as measured by DLQI throughout the study. Drug survival rate was elevated, demonstrating appropriate side effect management since few patients interrupted DMF because of tolerability problems.

Our results are comparable to those obtained in the Bridge study; nevertheless, there were differences in trial design and patients characteristics. Mrowietz et al., indeed, reported achievement of PASI50 in about $50 \%$ of patients and PASI75 in about $40 \%$ of patients treated with DMF for 16 weeks [11]. In our study, a subgroup analysis for face, genital and scalp locations was carried out for the first time, demonstrating a clinically significant 
Table 2 Clinical characteristics of patients who developsed COVID-19 positivity during the study

\begin{tabular}{|c|c|c|c|c|}
\hline Age & 53 & 57 & 65 & 67 \\
\hline Sex & Male & Male & Male & Male \\
\hline $\operatorname{BMI}\left(\mathrm{kg} / \mathrm{m}^{2}\right)$ & 26.0 & 27.5 & 24.8 & 28.4 \\
\hline $\begin{array}{l}\text { Age of plaque } \\
\text { psoriasis onset }\end{array}$ & 32 & 16 & 62 & 43 \\
\hline Comorbidity & Hypertension and dyslipidemia & $\begin{array}{l}\text { Hypertension } \\
\text { and } \\
\text { dyslipidemia }\end{array}$ & $\begin{array}{l}\text { Hypertension and cardiac } \\
\text { arrhythmia }\end{array}$ & Hypertension \\
\hline Previous treatments & Acitretin and topical treatment & $\begin{array}{l}\text { Ciclosporin and } \\
\text { topical } \\
\text { treatment }\end{array}$ & Topical treatment & $\begin{array}{l}\text { Ciclosporin and } \\
\text { topical } \\
\text { treatment }\end{array}$ \\
\hline $\begin{array}{l}\text { Mean clinical } \\
\text { characteristic }\end{array}$ & $\begin{array}{l}\text { PASI 18.1, PGA 4, DLQI 15, } \\
\text { nail PGA } 2\end{array}$ & $\begin{array}{l}\text { PASI 9, PGA 1, } \\
\text { DLQI 19, } \\
\text { face and scalp } \\
\text { PGA } 2\end{array}$ & $\begin{array}{l}\text { PASI 15, PGA 4, DLQI } \\
\text { 20, scalp PGA } 3\end{array}$ & $\begin{array}{l}\text { PASI 15.7, PGA } \\
\text { 2, DLQI } 15, \\
\text { scalp PGA } 4 \text {, } \\
\text { nail PGA } 3\end{array}$ \\
\hline $\begin{array}{l}\text { Week of DMF } \\
\text { treatment- } \\
\text { development of } \\
\text { SARS-Covid-2 } \\
\text { positivity }\end{array}$ & Week 5 & Week 2 & Week 26 & Week 12 \\
\hline $\begin{array}{l}\text { COVID-19 } \\
\text { symptomatology }\end{array}$ & $\begin{array}{l}\text { Fever, cough and general } \\
\text { malaise for } 10 \text { days, without } \\
\text { complication toward } \\
\text { interstitial pneumonitis }\end{array}$ & $\begin{array}{l}\text { No specific } \\
\text { symptoms }\end{array}$ & $\begin{array}{l}\text { Transient fever with auto- } \\
\text { resolution and } \\
\text { coexistent dysgeusia and } \\
\text { general malaise }\end{array}$ & $\begin{array}{l}\text { Loss of taste and } \\
\text { smell }\end{array}$ \\
\hline Hospitalization & No & No & No & No \\
\hline $\begin{array}{l}\text { DMF treatment } \\
\text { discontinuation }\end{array}$ & No & No & No & No \\
\hline
\end{tabular}

improvement in psoriatic lesions in difficult-totreat sites, as assessed by PGA.

Adverse events, such as flushing, diarrhea and gastric pain, although frequent, were well known, predictable, manageable and similar to those reported in different clinical real-life experiences and trials [10, 20-24].

The long-term observation showed a good drug retention rate since dropouts were limited and occurred in $29.54 \%$ patients. The rates of discontinuations were lower than those reported in the Bridge trial [3], with the new formulation of DMF (LAS41008) at $37.1 \%$ and
Fumaderm $^{\circledR}$ at $38.5 \%$, respectively, demonstrating that in real life the clinician's behavior in terms of dose adjustment and management of side effects may lead to a higher retention rate.

The effectiveness, registered in this real-life experience with DMF, becomes more interesting when we consider that patients who developed SARS-CoV-2 positivity during the study did not discontinue the current therapy and had a positive disease course. Indeed, Timpani et al. suggested that the immunomodulatory, anti-oxidative and anti-inflammatory properties 
of DMF could reduce the cytokine storm caused by severe COVID-19 [6]. Moreover, recent research demonstrated that the expression of Nrf2-dependent genes is suppressed in biopsies from COVID-19 patients and that treatment of cells with Nrf2-agonist 4-octyl-itaconate and DMF limits COVID-19 replication. DMF furthermore limits the release of pro-inflammatory cytokines in response to SARS-CoV-2 infection [25]. This observation is even more significant during the COVID-19 pandemic when the therapeutic choice is challenged by several concerns in terms of immunosuppression and risk of infection and the influence of traditional immunosuppressive drugs on the efficacy of vaccines $[26,27]$. Interestingly, although there is still not much evidence regarding the use of SARS-CoV-2 vaccine in patients with psoriasis treated with DMF, in patients with multiple sclerosis treated with DMF the vaccine response was not changed, suggesting that the vaccination should proceed immediately and without interruption of DMF treatment [28]. The findings of this study should be seen in light of some limitations related to the small sample size and the heterogeneous clinical evaluation for the retrospective observational nature of the study carried out in a real-life setting.

\section{CONCLUSIONS}

In conclusion, this real-life experience demonstrated that DMF treatment was effective and safe in patients with moderate-to-severe chronic plaque psoriasis including patients who developed SARS-CoV-2 positivity. The small number of patients with SARS-CoV-2 positivity could be attributed to the strict Italian lockdown and social distancing measures. The findings of this study have to be seen in light of some limitations, including the general small sample size, small number of patients with COVID-19 and heterogeneous clinical evaluation following from the retrospective observational nature of the study carried out in a real-life setting. Additional real-life research is needed to further investigate the use of DMF in patients with psoriasis and in particular conditions during the COVID-19 pandemic.

\section{ACKNOWLEDGEMENTS}

Funding. This study and the journal's Rapid Service Fee were supported by Almirall S.p.A. (provider: Thenewway Srl).

Medical Writing and Editorial Assistance. Medical writing assistance was provided by Irene Scagnol, Biologist with a PhD in Clinical Pharmacology, University of Milan, supported by Almirall S.p.A.

Authorship. All named authors meet the International Committee of Medical Journal Editors (ICMJE) criteria for authorship for this article, take responsibility for the integrity of the work as a whole, and have given their approval for this version to be published.

Author Contributions. Conceptualization: Maria Esposito, Anna Campanati, Alessandro Giunta, Anna Maria Offidani, Maria Concetta Fargnoli. Methodology: Maria Esposito, Anna Campanati, Gianluca Calianno, Federico Diotallevi. Formal analysis and investigation: Alessandro Giunta, Maria Esposito, Anna Campanati. Writing-original draft preparation: Irene Scagnol. Writing-review and editing: all authors. Supervision: Maria Concetta Fargnoli, Anna Maria Offidani, Luca Bianchi.

Disclosures. Maria Esposito has served as speaker and/or consultant for Abbvie, Almirall, Biogen, Celgene, Eli Lilly, Janssen, Leo Pharma, Novartis, Sanofi Genzyme and UCB. Anna Campanati has served as speaker and/or consultant for Abbvie, Almirall, Eli Lilly, Janssen, Leo Pharma, Novartis, Sanofi Genzyme and UCB. FD has served as speaker and/or consultant for Eli Lilly, Novartis. AO has served on advisory boards, received honoraria for lectures and research grants from Almirall, Abbvie, Galderma, Leo Pharma, Celgene, Pierre Fabre, UCB, Eli Lilly, Pfizer, Janssen, Novartis and SanofiGenzyme. Alessandro Giunta has served as speaker and/or consultant for Abbvie, Biogen, Eli Lilly, Pfizer and UCB. Gianluca Calianno has nothing to disclose. Luca Bianchihas served on advisory boards and received honoraria for 
lectures and research grants from Almirall, Abbvie, Leo Pharma, Amgen, Biogen, UCB, Eli Lilly, Janssen, Novartis and Sanofi-Genzyme. Federico Diotallevi has served as speaker and/or consultant for Eli Lilly and Novartis. Anna Maria Offidani has served on advisory boards and received honoraria for lectures and research grants from Almirall, Abbvie, Galderma, Leo Pharma, Celgene, Pierre Fabre, UCB, Eli Lilly, Pfizer, Janssen, Novartis and Sanofi-Genzyme. Maria Concetta Fargnoli has served on advisory boards, received honoraria for lectures and research grants from Almirall, Abbvie, Galderma, Leo Pharma, Mylan, Medac Pharma, Celgene, Pierre Fabre, UCB, Eli Lilly, Pfizer, Janssen, Novartis, Sanofi-Genzyme, Roche, Sunpharma and MSD.

Compliance with Ethics Guidelines. The investigation was conducted in accordance with the Helsinki Declaration, and patients signed a declaration allowing the use of clinical records for scientific purposes. Ethics committee approval for retrospective studies was not required.

Data Availability. Data available on request from the authors.

Open Access. This article is licensed under a Creative Commons Attribution-NonCommercial 4.0 International License, which permits any non-commercial use, sharing, adaptation, distribution and reproduction in any medium or format, as long as you give appropriate credit to the original author(s) and the source, provide a link to the Creative Commons licence, and indicate if changes were made. The images or other third party material in this article are included in the article's Creative Commons licence, unless indicated otherwise in a credit line to the material. If material is not included in the article's Creative Commons licence and your intended use is not permitted by statutory regulation or exceeds the permitted use, you will need to obtain permission directly from the copyright holder. To view a copy of this licence, visit http://creativecommons.org/licenses/by$\mathrm{nc} / 4.0 /$.

\section{REFERENCES}

1. van de Kerkhof PCM, Loewe R, Mrowietz U, Falques M, Pau-Charles I, Szepietowski JC. Quality of life outcomes in adults with moderate-to-severe plaque psoriasis treated with dimethylfumarate (DMF): a post hoc analysis of the BRIDGE study. J Eur Acad Dermatol Venereol. 2020;34(1):119-26.

2. Balak DMW, Gerdes S, Parodi A, Salgado-Boquete L. Long-term safety of oral systemic therapies for psoriasis: a comprehensive review of the literature. Dermatol Ther (Heidelb). 2020;10(4):589-613.

3. Mrowietz U, Barker J, Boehncke WH, et al. Clinical use of dimethyl fumarate in moderate-to-severe plaque-type psoriasis: a European expert consensus. J Eur Acad Dermatol Venereol. 2018;32(Suppl 3): 3-14.

4. Balogh EA, Bashyam AM, Ghamrawi RI, Feldman SR. Emerging systemic drugs in the treatment of plaque psoriasis. Expert Opin Emerg Drugs. 2020;25(2):89-100.

5. Blair HA. Dimethyl fumarate: a review in moderate to severe plaque psoriasis. Drugs. 2018;78(1): $123-30$.

6. Timpani CA, Rybalka E. Calming the (cytokine) storm: dimethyl fumarate as a therapeutic candidate for COVID-19. Pharmaceuticals (Basel). 2020;14(1):15.

7. Chiricozzi A, Gisondi P, Bellinato F, Girolomoni G. Immune response to vaccination in patients with psoriasis treated with systemic therapies. Vaccines (Basel). 2020;8(4):769.

8. Kourakis S, Timpani CA, de Haan JB, Gueven N, Fischer D, Rybalka E. Dimethyl fumarate and its esters: a drug with broad clinical utility? Pharmaceuticals (Basel). 2020;13(10):306.

9. Sulaimani J, Cluxton D, Clowry J, et al. Dimethyl fumarate modulates the Treg-Th17 cell axis in psoriasis patients. Br J Dermatol. 2021;184(3): 495-503.

10. Lijnen R, Otters E, Balak D, Thio B. Long-term safety and effectiveness of high-dose dimethylfumarate in the treatment of moderate to severe psoriasis: a prospective single-blinded follow-up study. J Dermatol Treat. 2016;27(1):31-6.

11. Mrowietz U, Szepietowski JC, Loewe R, et al. Efficacy and safety of LAS41008 (dimethyl fumarate) in adults with moderate-to-severe chronic plaque psoriasis: a randomized, double-blind, Fumaderm ${ }^{\circledR}$ and placebo-controlled trial (BRIDGE). Br J Dermatol. 2017;176(3):615-23. 
12. Dickel H, Bruckner T, Altmeyer P. Long-term reallife safety profile and effectiveness of fumaric acid esters in psoriasis patients: a single-centre, retrospective, observational study. J Eur Acad Dermatol Venereol. 2018;32(10):1710-27.

13. Reich K, Thaci D, Mrowietz U, Kamps A, Neureither M, Luger T. Efficacy and safety of fumaric acid esters in the long-term treatment of psoriasis-a retrospective study (FUTURE). J Dtsch Dermatol Ges. 2009;7(7):603-11.

14. Sator P, Loewe R, Zamani O, et al. Dimethyl fumarate is efficacious in severe plaque psoriasis: post hoc analysis from the BRIDGE trial in Austria. Wien Klin Wochenschr. 2019;131(19-20):485-92.

15. Nast A, Smith C, Spuls PI, et al. EuroGuiDerm Guideline on the systemic treatment of Psoriasis vulgaris-part 2: specific clinical and comorbid situations. J Eur Acad Dermatol Venereol. 2021;35(2): 281-317.

16. Skilarence, Summary of Product Characteristic. Last edition June 2021. https://www.ema.europa.eu

17. Fredriksson T, Pettersson U. Severe psoriasis-oral therapy with a new retinoid. Dermatologica. 1978;157:238-44.

18. Nast A, Gisondi P, Ormerod AD, et al. European S3Guidelines on the systemic treatment of psoriasis vulgaris-update 2015-short version-EDF in cooperation with EADV and IPC. J Eur Acad Dermatol Venereol. 2015;29:2277-94.

19. Finlay AY, Khan GK. Dermatology Life Quality Index (DLQI) - a simple practical measure for routine clinical use. Clin Exp Dermatol. 1994;19: 210-6.

20. Mrowietz U, Van de Kerkhof P, Schoenenberger A, et al. Efficacy of dimethyl fumarate treatment for moderate-to-severe plaque psoriasis: presentation extracts from the 29th EADV virtual congress,
29-31 October. Expert Rev Clin Immunol. 2020;2021:1-11.

21. Falkvoll S, Gerdes S, Mrowietz U. Switch of psoriasis therapy from a fumaric acid ester mixture to dimethyl fumarate monotherapy: results of a prospective study. J Dtsch Dermatol Ges. 2019;17(9):906-12.

22. Reszke R, Szepietowski JC. A safety evaluation of dimethyl fumarate in moderate-to-severe psoriasis. Expert Opin Drug Saf. 2020;19(4):373-80.

23. Corazza M, Odorici G, Conti A, et al. Dimethyl fumarate treatment for psoriasis in a real-life setting: a multicentric retrospective study. Dermatol Ther. 2021;34(5):e15066.

24. Filippi F, Sacchelli L, DI Altobrando A, Pileri A, Bardazzi F. Dimethyl fumarate: a case of improvement of alcoholic steatohepatitis in an elderly psoriatic patient. Ital J Dermatol Venerol. 2021.

25. Olagnier D, Farahani E, Thyrsted J, et al. SARSCoV2-mediated suppression of NRF2-signaling reveals potent antiviral and anti-inflammatory activity of 4-octyl-itaconate and dimethyl fumarate. Nat Commun. 2020;11(1):4938.

26. Campanati A, Brisigotti V, Diotallevi F, et al. Active implications for dermatologists in 'SARS-CoV-2 ERA': personal experience and review of literature. J Eur Acad Dermatol Venereol. 2020;34(8):1626-32.

27. Talamonti M, Galluzzo M, Chiricozzi A, et al. Characteristic of chronic plaque psoriasis patients treated with biologics in Italy during the COVID-19 Pandemic: risk analysis from the PSO-BIO-COVID observational study. Expert Opin Biol Ther. 2021;21(2):271-7.

28. Al Jumah M, Abulaban A, Aggad H, et al. Managing multiple sclerosis in the Covid19 era: a review of the literature and consensus report from a panel of experts in Saudi Arabia. Mult Scler Relat Disord. 2021;51:102925. 